Erratum

\title{
Erratum to "Economic Analysis for Setting Appropriate Repair Cycles on the Fixed Materials and Facilities in the Public Rental Housing"
}

\author{
Sung-Min Choi ${ }^{1}$ and Yeon-Sil Lee ${ }^{2}$ \\ ${ }^{1}$ Building and Urban Research Institute, Korea Institute of Civil Engineering and Building Technology, \\ 283 Goyang-daero, Ilsanseo-gu, Goyang-si, Gyeonngi-do 10223, Republic of Korea \\ ${ }^{2}$ Research Institute of Construction Technology, Seoul National University of Science and Technology, \\ 232 Gongneung-ro, Nowon-gu, Seoul 139-743, Republic of Korea
}

Correspondence should be addressed to Yeon-Sil Lee; flyduck74@naver.com

Received 9 July 2017; Accepted 31 July 2017; Published 20 September 2017

Copyright (C) 2017 Sung-Min Choi and Yeon-Sil Lee. This is an open access article distributed under the Creative Commons Attribution License, which permits unrestricted use, distribution, and reproduction in any medium, provided the original work is properly cited.

In the article titled "Economic Analysis for Setting Appropriate Repair Cycles on the Fixed Materials and Facilities in the Public Rental Housing" [1], there was an error in the Acknowledgments section, which should be corrected as follows:

This research was supported by a grant (Code 11-Technology Innovation-F04) from Construction Technology Research Program (CTIP) funded by Ministry of Land, Infrastructure and Transport.

\section{References}

[1] S.-M. Choi and Y.-S. Lee, "Economic analysis for setting appropriate repair cycles on the fixed materials and facilities in the public rental housing," Advances in Materials Science and Engineering, vol. 2016, Article ID 7423801, 10 pages, 2016. 

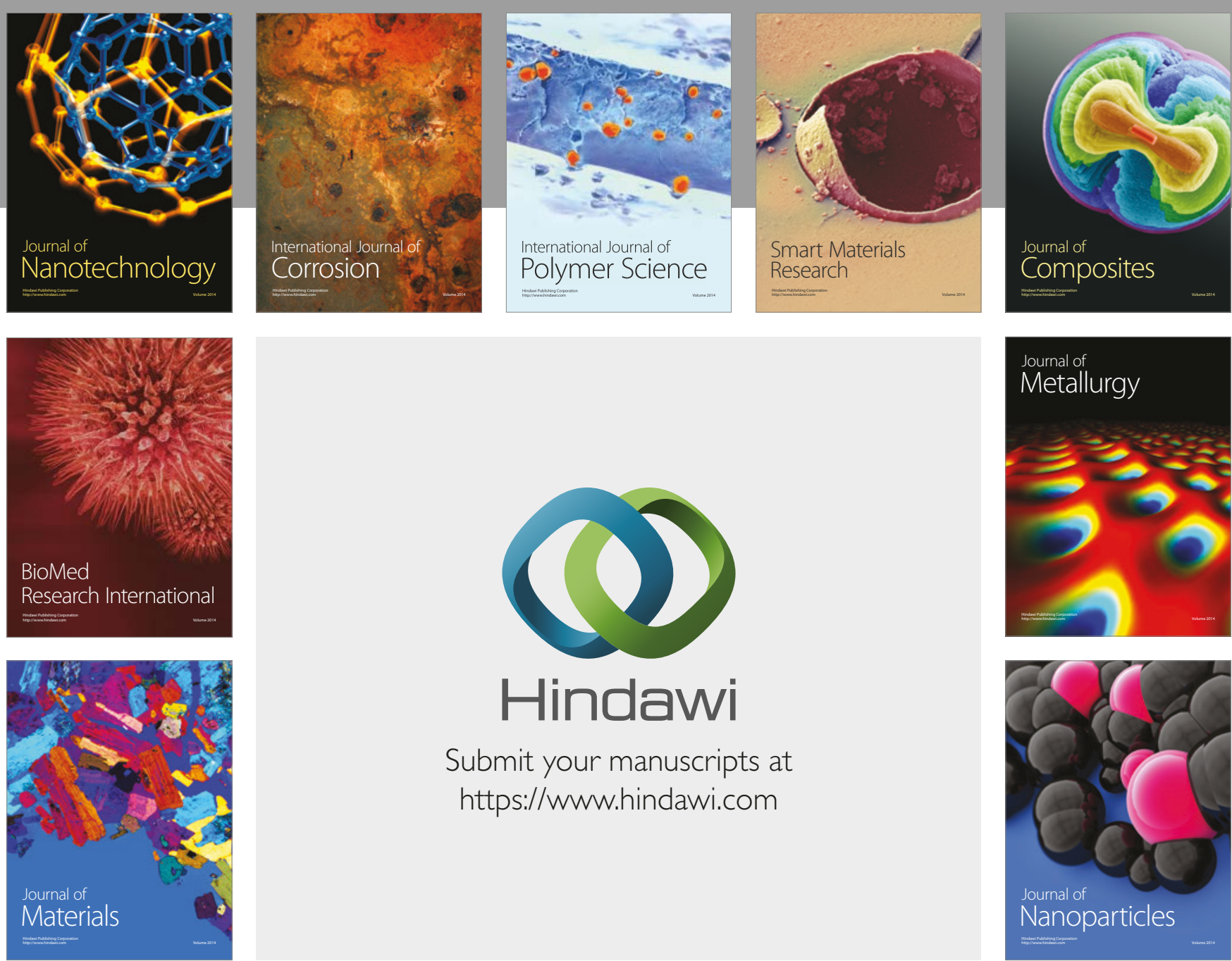

\section{Hindawi}

Submit your manuscripts at

https://www.hindawi.com
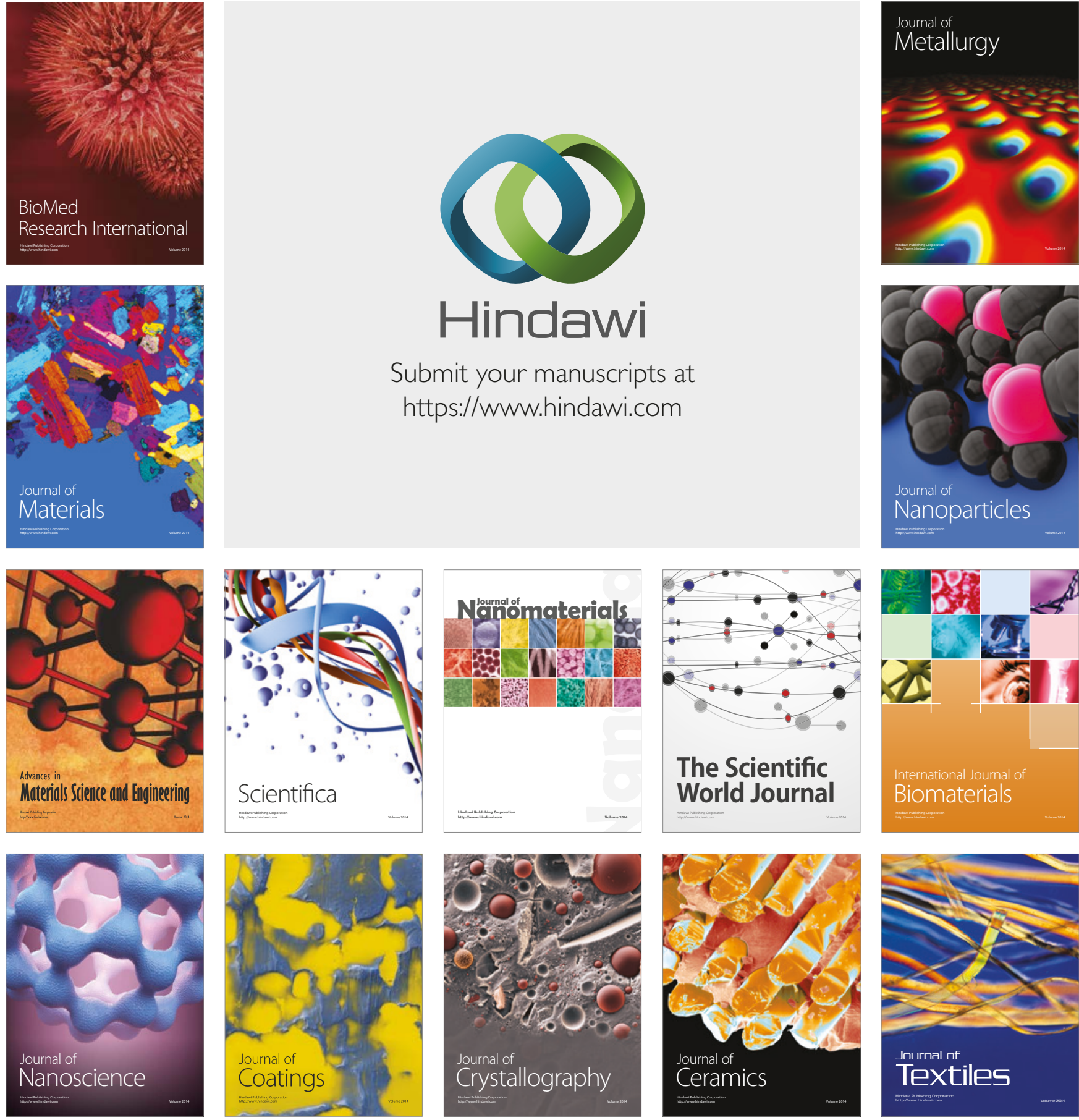

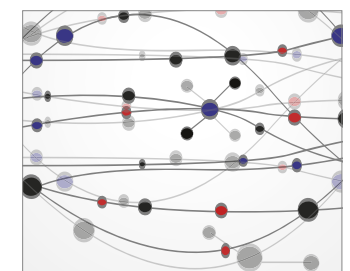

The Scientific World Journal
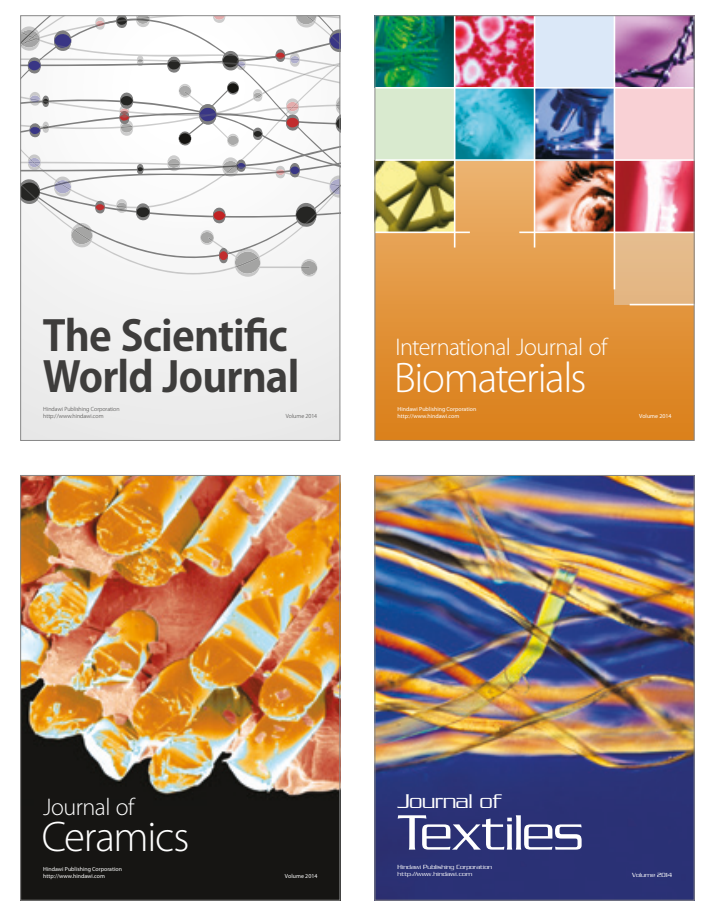